\title{
Spring melt pond fraction in the Canadian Arctic Archipelago predicted from RADARSAT-2
}

\author{
Stephen E. L. Howell ${ }^{1}$, Randall K. Scharien ${ }^{2}$, Jack Landy ${ }^{3}$, and Mike Brady ${ }^{1}$ \\ ${ }^{1}$ Climate Research Division, Environment and Climate Change Canada, Toronto, M3H 5T4, Canada \\ ${ }^{2}$ Department of Geography, University of Victoria, Victoria, V8W 2Y2, Canada \\ ${ }^{3}$ School of Geographical Sciences, University of Bristol, Bristol, BS8 1QU, UK
}

Correspondence: Stephen E. L. Howell (stephen.howell@canada.ca)

Received: 22 June 2020 - Discussion started: 2 July 2020

Revised: 26 October 2020 - Accepted: 13 November 2020 - Published: 21 December 2020

\begin{abstract}
Melt ponds form on the surface of Arctic sea ice during spring, influencing how much solar radiation is absorbed into the sea ice-ocean system, which in turn impacts the ablation of sea ice during the melt season. Accordingly, melt pond fraction $\left(f_{\mathrm{p}}\right)$ has been shown to be a useful predictor of sea ice area during the summer months. Sea ice dynamic and thermodynamic processes operating within the narrow channels and inlets of the Canadian Arctic Archipelago (CAA) during the summer months are difficult for model simulations to accurately resolve. Additional information on $f_{\mathrm{p}}$ variability in advance of the melt season within the CAA could help constrain model simulations and/or provide useful information in advance of the shipping season. Here, we use RADARSAT-2 imagery to predict and analyze peak melt pond fraction $\left(f_{\mathrm{pk}}\right)$ and evaluate its utility to provide predictive information with respect to sea ice area during the melt season within the CAA from 2009-2018. The temporal variability of RADARSAT- $2 f_{\mathrm{pk}}$ over the 10 -year record was found to be strongly linked to the variability of mean April multi-year ice area with a statistically significant detrended correlation $(R)$ of $R=-0.89$. The spatial distribution of RADARSAT- $2 f_{\mathrm{pk}}$ was found to be in excellent agreement with the sea ice stage of development prior to the melt season. RADARSAT- $2 f_{\mathrm{pk}}$ values were in good agreement with $f_{\mathrm{pk}}$ observed from in situ observations but were found to be $\sim 0.05$ larger compared to MODIS $f_{\mathrm{pk}}$ observations. Dynamically stable sea ice regions within the CAA exhibited higher detrended correlations between RADARSAT- $2 f_{\mathrm{pk}}$ and summer sea ice area. Our results show that RADARSAT$2 f_{\mathrm{pk}}$ can be used to provide predictive information about
\end{abstract}

summer sea ice area for a key shipping region of the Northwest Passage.

\section{Introduction}

Arctic sea ice extent during the summer months has declined considerably over the satellite record (Serreze et al., 2007; Stroeve et al., 2012; Peng and Meier, 2017). Surface melt ponds, which form on sea ice during the spring, play an important role in the decay of sea ice and seasonal reduction in ice extent because they influence how much solar radiation is absorbed into the sea ice-ocean system (Eicken et al., 2004). Specifically, the accumulation of meltwater on the surface of the sea ice lowers the albedo from $\sim 0.8$ to between $0.2-0.4$ and enhances melt (Perovich et al., 2002). The topographical constraints over multi-year ice (MYI) imposed by hummocks typically result in MYI exhibiting a lower melt pond fraction $\left(f_{\mathrm{p}}\right)$ compared to seasonal first-year ice (FYI) (Grenfell and Perovich, 2004; Polashenski et al., 2012; Landy et al., 2015). With Arctic sea ice transitioning from a MYI- to FYIdominated icescape (Maslanik et el., 2011), the lower $f_{\mathrm{p}}$ of MYI will gradually be replaced with the higher $f_{\mathrm{p}}$ of FYI, facilitating even more sea ice energy absorption and further enhancing sea ice melt (Perovich and Polashenski, 2012).

Predicting the state of Arctic sea ice several months in advance is challenging, and recently the sea ice prediction community has focused efforts on the development and utilization of dynamical forecast models (e.g. Chevallier et al., 2013; Sigmond et al., 2013; Guemas et al., 2016). Despite these recent efforts, rapidly changing Arctic sea ice condi- 
tions will continue to necessitate improved sea ice forecasting capabilities (Eicken, 2013). Accordingly, prognostic $f_{\mathrm{p}}$ schemes have been integrated in climate models and have shown to exert a strong influence on summer sea ice area and extent (Flocco et al., 2010, 2012). Schröder et al. (2014) found a strong correlation between model-simulated May $f_{\mathrm{p}}$ and the observed September sea ice extent. Observed $f_{\mathrm{p}}$ has also demonstrated significant predictive skill for September ice extent from late July onwards (Liu et al., 2015). However, while $f_{\mathrm{p}}$ estimates for the entire Arctic can be provided by model simulations, more representative and higher spatial resolution observational estimates at regional and pan-Arctic scales are much more difficult to obtain.

Optical remote sensing is the most widely utilized approach to estimate large-scale $f_{\mathrm{p}}$ from space (e.g. Markus et al., 2003; Tschudi et al., 2008; Rösel et al., 2012; Istomina et al., 2015; Webster et al., 2015; Lee et al., 2020) but cloud cover remains a significant problem. Techniques for retrieving $f_{\mathrm{p}}$ using advanced quad-polarization and compactpolarization mode synthetic aperture radar (SAR) imagery, at $\mathrm{C}$ - and $\mathrm{X}$-band frequencies, have also been developed (Scharien et al., 2014; Fors et al., 2017; Li et al., 2017), but they are limited in systematic spatial application because the required polarization modes are not always available from wide-swath imagery. However, using the winter backscatter from widely available Sentinel-1 SAR imagery, Scharien et al. (2017) recently demonstrated a technique for predicting spring peak melt pond fraction $\left(f_{\mathrm{pk}}\right)$ over the entire Canadian Arctic Archipelago (CAA) 3-4 months in advance of melt pond formation. These $f_{\mathrm{pk}}$ predictions have potential utility in seasonal summer sea ice area and extent forecasts as early as April.

The CAA is a collection of islands located in northern Canada (Fig. 1) whose waterways are sea ice covered between fall and spring. It is an active region for marine shipping and has recently experienced an increase in summer shipping activity (Pizzolato et al., 2014). Model simulations have been utilized to understand the current and predicted future variability of sea ice conditions in the CAA (e.g. Dumas et al., 2006; Sou and Flato, 2009, Howell et al., 2016; Laliberté et al., 2016; Hu et al., 2018; Laliberté et al., 2018). However, modelling the CAA still remains challenging because complex sea ice dynamic and thermodynamic processes are often not accurately resolved in its narrow channels and inlets. In addition, the response of the CAA to climatic change is perhaps counter-intuitive as longer melt seasons are resulting in increased MYI import from the Arctic Ocean during the summer months (Howell and Brady, 2019). Since $f_{\mathrm{pk}}$ is linked to summer sea ice melt processes (e.g. Eicken et al., 2004; Skyllingstad and Polashenski, 2018) additional information on $f_{\mathrm{pk}}$ variability within the CAA could improve our understanding of regional summer melt processes, help constrain model simulations, and facilitate safer shipping activity in upcoming years.

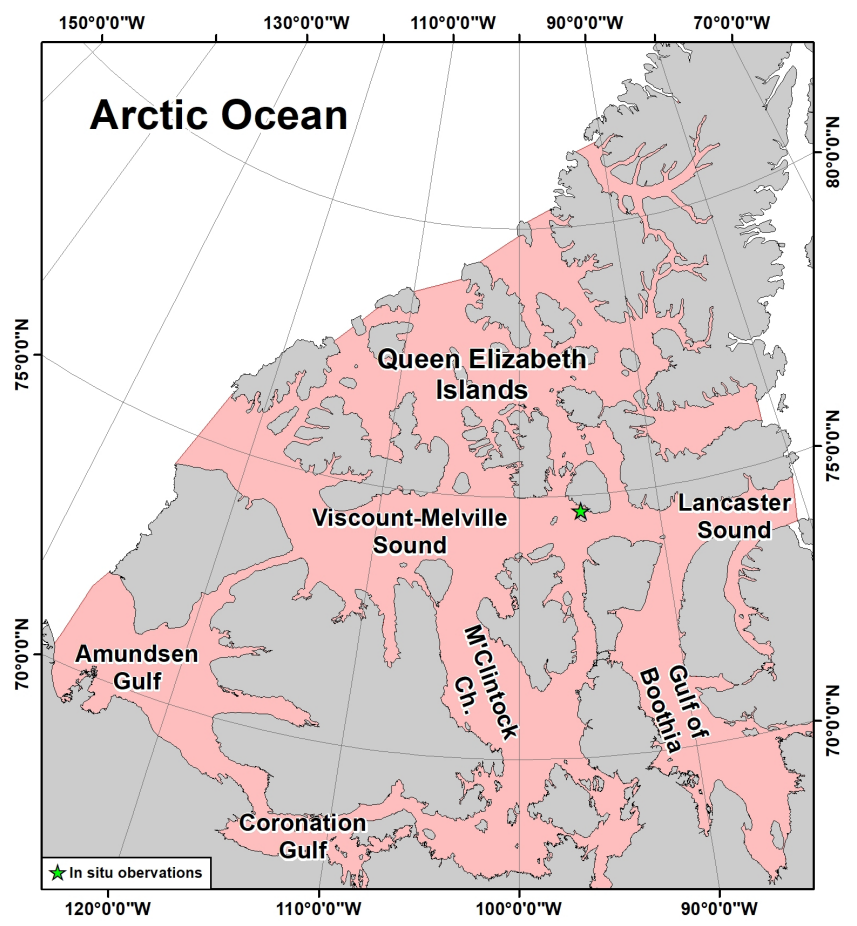

Figure 1. Map of the Canadian Arctic Archipelago region (red shading). The green star indicates the location of the lidar and aerial photograph observations.

In this study, we extend the work of Scharien et al. (2017) and investigate predicted $f_{\mathrm{pk}}$ variability within the CAA over the longer-term record available from RADARSAT2. Specifically, (i) we estimate $f_{\mathrm{pk}}$ in the CAA using RADARSAT-2; (ii) evaluate the spatiotemporal variability of $f_{\mathrm{pk}}$ in the CAA from 2009-2018; (iii) compare RADARSAT-2 $f_{\mathrm{pk}}$ values to Sentinel-1 $f_{\mathrm{pk}}$ values from Scharien et al. (2017), in situ $f_{\mathrm{p}}$ observations from Landy et al. (2014) and Moderate Resolution Image Spectroradiometer (MODIS) $f_{\mathrm{p}}$ values from Rösel et al. (2012); and (iv) investigate the utility of RADARSAT- $2 f_{\mathrm{pk}}$ to provide predictive information about sea ice area in the CAA during the summer melt season.

\section{Methodology}

\subsection{Data}

The primary dataset used in this analysis was $5.405 \mathrm{GHz}$ (wavelength, $\lambda=5.5 \mathrm{~cm}$; C-band) SAR imagery in ScanSAR wide mode at $\mathrm{HH}$ polarization from RADARSAT-2 acquired over the CAA (Fig. 1) in April from 2009-2018 (Table 1). RADARSAT-2 ScanSAR wide mode imagery has a spatial resolution of $100 \mathrm{~m}$ with an incidence angle range of 20.0 to $49.3^{\circ}$. We limited our analysis to only RADARSAT- 2 images at $\mathrm{HH}$ polarization because Scharien et al. (2017) found HV produced noisy results in addition to there not being suffi- 
Table 1. Number of RADARSAT-2 images acquired over the Canadian Arctic Archipelago in April for 2009-2018.

\begin{tabular}{rr}
\hline Year & $\begin{array}{r}\text { RADARSAT-2 } \\
\text { image count }\end{array}$ \\
\hline 2009 & 90 \\
2010 & 138 \\
2011 & 149 \\
2012 & 149 \\
2013 & 188 \\
2014 & 159 \\
2015 & 133 \\
2016 & 159 \\
2017 & 151 \\
2018 & 144 \\
\hline
\end{tabular}

cient imagery at $\mathrm{HV}$ polarization in the early period of the RADARSAT- 2 record to cover CAA in April.

In situ observations of $f_{\mathrm{p}}$ on landfast FYI were obtained in 2 consecutive years from sites in the CAA using a terrestrial light detection and ranging (lidar) system (Landy et al., 2014) (Fig. 1, green star). In 2011, the site was located in Allen Bay on FYI with relatively rough surface topography, whereas in 2012, the site was located in Resolute Passage on FYI with relatively smooth topography. At each site, time series of $f_{\mathrm{p}}$ observations were collected within the same $100 \times 100 \mathrm{~m}$ area of the ice over a 2- to 3-week period following melt onset, covering three of the four stages of melt pond evolution detailed in Eicken et al. (2002). The lidar system produces dense measurements over snow or sea ice, with specular reflection over melt ponds allowing melt pond fractions to be retrieved with an accuracy better than 5\% (Landy et al., 2014). These observations allow us to evaluate how well RADARSAT-2 resolves $f_{\mathrm{pk}}$ of seasonally evolving sea ice coverage.

Aerial photographs of estimated $f_{\mathrm{p}}$ directly over the lidar site and the adjacent sea ice area away from land and open water were also obtained on 22 June 2012. The aerial photographs have a $0.22 \mathrm{~m}$ pixel resolution, covering $750 \mathrm{~m}$ by $750 \mathrm{~m}$. In total, 123 aerial photographs of $f_{\mathrm{p}}$ were used, and a complete description of the dataset is provided in Scharien et al. (2014).

Finally, we made use of $8 \mathrm{~d}$ composite satellite observations of $f_{\mathrm{p}}$ obtained from the MODIS Arctic melt pond cover fraction dataset that has a spatial resolution of $12.5 \mathrm{~km}$ for the period of 2009-2011 (Rösel et al., 2012) and weekly sea ice area and stage of development observations obtained from the Canadian Ice Service Digital Archive (CISDA) regional ice charts for the period of 2009-2018 (Tivy et al., 2011).

\subsection{Estimating $f_{\mathrm{pk}}$ from RADARSAT-2}

RADARSAT- $2 f_{\mathrm{pk}}$ was determined using a modified approach to that described by Scharien et al. (2017). Their approach determines the second stage of the seasonal melt pond evolution cycle when $f_{\mathrm{p}}$ is at its peak (Eicken et al., 2002; Polashenski et al., 2012) using Sentinel-1 Extra Wide (EW) swath imagery obtained during April within the CAA. April corresponds to late winter sea ice conditions in the CAA, when sea ice growth has reached its maximum and spring warming has yet to begin. Their approach was developed by relating the winter period $\mathrm{HH}$ gamma nought $\left(\gamma^{\circ}\right)$ backscatter in decibels (dB) from Sentinel-1 to $f_{\mathrm{pk}}$ observations in $1.7 \mathrm{~m}$ spatial resolution GeoEye-1 imagery, from spatially coincident image segments that represented homogeneous FYI and MYI regions. The result was that $\gamma^{\circ}$ can be converted to $f_{\mathrm{pk}}$ using the following equation:

$f_{\mathrm{pk}}=-0.221-0.041\left(\gamma^{\circ}\right)$.

In Eq. (1), $\gamma^{\circ}$ was found to explain $73 \%$ of the variability in $f_{\mathrm{pk}}$ (Scharien et al., 2017).

In this study, all the available $\mathrm{HH}$ polarization RADARSAT-2 imagery over the CAA in April from 2009-2018 (Table 1) was first calibrated to $\gamma^{\circ}$ which minimizes the influence of incidence angle more so than with sigma nought $\left(\sigma^{\circ}\right)$ (Small, 2011). RADARSAT-2 images were then speckle filtered using a $5 \times 5$ Lee filter and spatially registered to a common map projection. Finally, $\gamma^{\circ}$ was converted to $f_{\mathrm{pk}}$ by applying Eq. (1) to each RADARSAT- 2 image. For each year, the corresponding RADARSAT- $2 f_{\mathrm{pk}}$ images in April were mosaicked together to cover the entire spatial domain of the CAA. Constructing a mosaic over a large region such as the CAA presents certain challenges with SAR imagery, particularly incidence angle variability. Even with the use of $\gamma^{\circ}$, Scharien et al. (2017) found that because of varying incidence angles associated with different ScanSAR images that $f_{\mathrm{pk}}$ striping can still occur within the CAA in the mosaicked image. Our approach here was to average out incidence angle variability by taking advantage of a large amount of overlapping RADARSAT-2 imagery within the CAA (i.e. 90 to 159 images; Table 1) together with the fact that the majority of the sea ice in the CAA is landfast (immobile) during April, which results in a temporally stable $f_{\mathrm{pk}}$ for all April images. To produce a RADARSAT- $2 f_{\mathrm{pk}}$ mosaic within the CAA for each year, we calculated the mean $f_{\mathrm{pk}}$ for each overlapping pixel using all of each year's RADARSAT-2 April images that effectively helped to reduce $f_{\mathrm{pk}}$ striping across the CAA.

The root-mean-square error (RMSE) of $f_{\mathrm{pk}}$ based on Eq. (1) is 0.085 (Scharien et al., 2017). While calculating the mean $f_{\mathrm{pk}}$ of the overlapping image pixels helps reduce striping across the CAA, it also adds additional uncertainty and its effectiveness depends on the number of overlaps. In order to quantify the additional uncertainty ( $\mathrm{RMSE}_{R 2}$ ), we used the mean and maximum standard deviation of RADARSAT$2 f_{\mathrm{pk}}$ of all pixels within the CAA calculated from 2009$2018\left(f_{\text {std }}\right)$ together with a range of pixel overlaps $(n)$ in the 


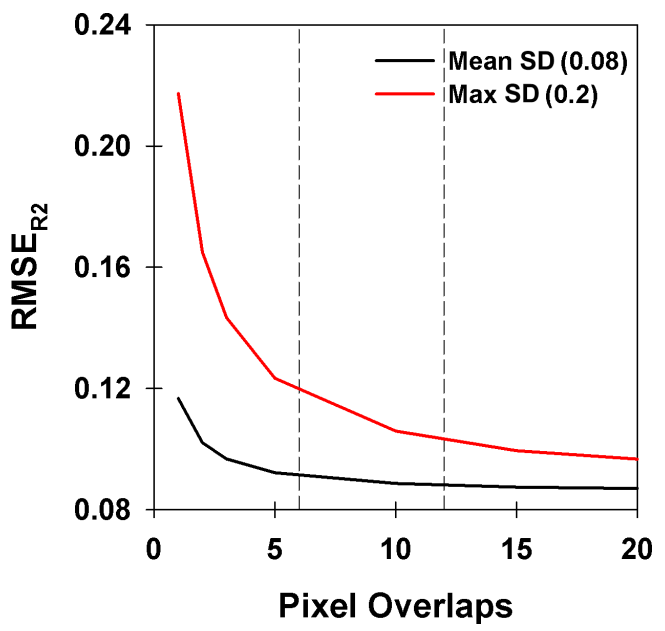

Figure 2. The root-mean-square error of RADARSAT-2 peak melt pond fraction values $\left(\mathrm{RMSE}_{R 2}\right)$ with increasing number of RADARSAT-2 pixel overlaps. The vertical dashed lines indicate the range of typical overlap from 2009-2018.

following equation:

$\operatorname{RMSE}_{R 2}=\left[\left(f_{\text {std }} / n^{0.5}\right)^{2}+0.085^{2}\right]^{0.5}$.

Since RADARSAT-2 imagery is acquired operationally, overlapping images vary interannually but pixel overlaps across the CAA were typically between $6-12$. Figure 2 illustrates the RMSE $\mathrm{R}_{R 2}$ values for a range of pixel overlaps using the 2009-2018 mean $f_{\text {std }}$ value of 0.08 and the 2009-2018 maximum $f_{\text {std }}$ value of 0.2 . For the maximum $f_{\text {std }}$ with pixel overlaps between 6-12 the $\mathrm{RMSE}_{R 2}$ ranges from $0.10-0.12$.

\section{Results and discussion}

\subsection{RADARSAT-2 $f_{\mathrm{pk}}$ spatial and temporal variability from 2009-2018}

The spatial distribution of mosaicked RADARSAT- $2 f_{\mathrm{pk}}$ and pre-melt season (i.e. April) and sea ice stage of developed conditions in the CAA for the 2009-2018 time period are shown in Figs. 3 and 4, respectively. Lower $f_{\text {pk }}$ values are located primarily in the northern regions of the CAA (Queen Elizabeth Islands), Viscount Melville Sound, and the M'Clintock Channel where the majority of the CAA's MYI is typically found. The shallow bays and narrow channels located throughout the CAA exhibit high $f_{\mathrm{pk}}$ values and these regions are typically associated with smooth FYI whereas rougher ice regions (i.e. Gulf of Boothia) are associated with lower $f_{\mathrm{pk}}$ values. We should expect a lower $f_{\mathrm{pk}}$ over MYI regions compared to FYI regions (Grenfell and Perovich, 2004; Perovich and Polashenski, 2012), and indeed the overall spatial distribution of RADARSAT- $2 f_{\mathrm{pk}}$ is in excellent agreement with the spatial distribution of sea ice stage of development prior to the melt season for all years.
Figure 5a shows the time series of RADARSAT- $2 f_{\mathrm{pk}}$ variability together with mean April MYI area in the CAA from 2009-2018. Over the 10-year record, the mean RADARSAT$2 f_{\mathrm{pk}}$ was 0.47 and ranged from a low of 0.43 in 2009 to a high of 0.52 in 2013 . The temporal variability in RADARSAT- $2 f_{\mathrm{pk}}$ is reflected in the variability of April MYI area within the CAA over the 10-year record with a statistically significant detrended correlation $(R)$ of $R=-0.89$. The RADARSAT- $2 f_{\mathrm{pk}}$ linkage with April MYI area is particularly evident from 2011 and 2012 which were very light sea ice years within the CAA whereby a considerable amount of the CAA's MYI area was lost during the summer melt season (Howell et al., 2013), and this resulted in 2012 and 2013 (i.e. the years following extreme melt) being the two highest RADARSAT-2 $f_{\text {pk }}$ years from 2009-2018 (Fig. 3d-e). MYI area within in the CAA then increased following these light ice years and RADARSAT $f_{\mathrm{pk}}$ began to respond accordingly. In fact, there has always been a period of MYI recovery following light ice years with either MYI grown in situ and/or advected from Arctic Ocean into the CAA and gradually migrating to the CAA's southern regions (Howell et al., 2013). Figure $5 \mathrm{~b}$ illustrates the standard deviation of RADARSAT$2 f_{\mathrm{pk}}$ from 2009-2018 and spatially reflects the process of MYI flowing southward through the CAA as RADARSAT-2 $f_{\mathrm{pk}}$ was more variable in the MYI regions of the CAA compared to regions where FYI dominates the regional icescape.

What is interesting in Fig. 5a is that the mean RADARSAT- $2 f_{\mathrm{pk}}$ in 2009 was lower than all years from 2014-2018 (with the exception of 2016) despite the CAA containing less MYI area. In addition, 2017 and 2018 exhibited a larger spatial coverage of MYI compared to 2009 (Fig. $4 \mathrm{a}, \mathrm{i}-\mathrm{j}$ ). We suggest that higher RADARSAT- $2 f_{\mathrm{pk}}$ in recent years is a result of Arctic Ocean MYI entering the CAA being younger and thinner than in 2009 (Howell and Brady, 2019) with smoother surface topography, thereby having a higher summer melt pond coverage (Landy et al., 2015). This seems to be particularly evident in the Viscount Melville Sound and M'Clintock Channels regions when comparing 2009 (Fig. 3a) with 2017 (Fig. 3i) and 2018 (Fig. 3j). Indeed, several studies have reported considerable decreases in the age and thickness of Arctic Ocean MYI north of the CAA in recent years (e.g. Kwok, 2018; Petty et al., 2020; Tschudi et al., 2020)

\subsection{Comparison of RADARSAT-2 $f_{\mathrm{pk}}$ with Sentinel-1, in situ, and MODIS}

Frequency distributions of RADARSAT- $2 f_{\mathrm{pk}}$ and Sentinel$1 f_{\mathrm{pk}}$ from Scharien et al. (2017) in the CAA for 2016 and 2017 are shown in Fig. 6. Sentinel-1 appears to estimate more regions of lower $f_{\mathrm{pk}}$ compared to RADARSAT-2 which are typically associated with MYI. Whereas RADARSAT-2 estimates more regions of higher $f_{\mathrm{pk}}$ which are typically associated with smooth FYI. We consider these subtle differences to be primarily the result of taking the mean of all 

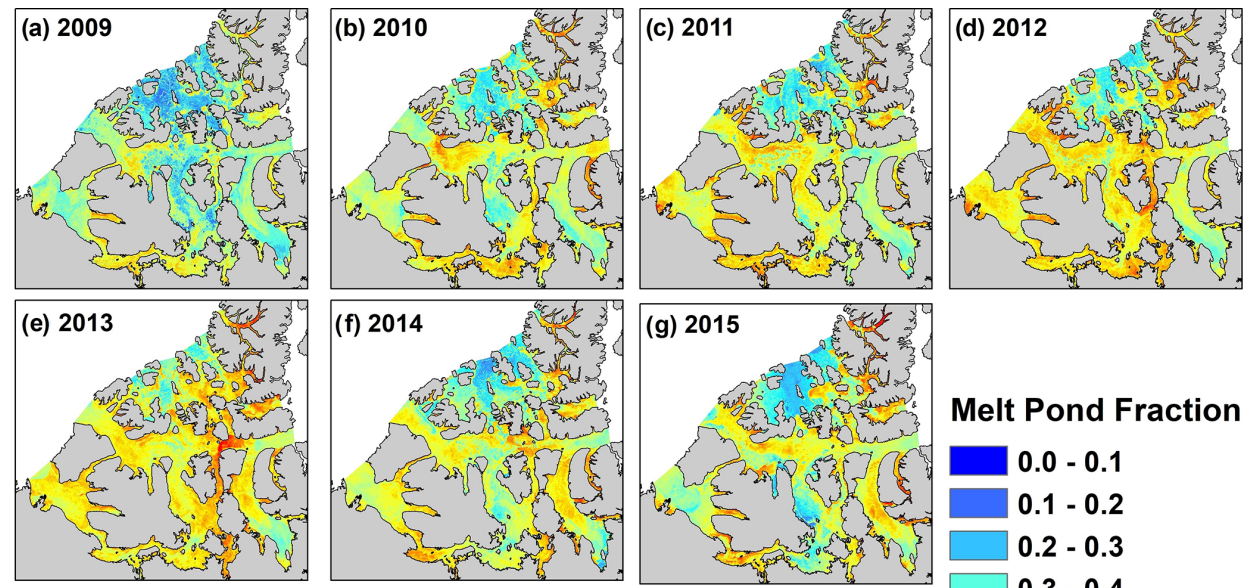

\section{Melt Pond Fraction}
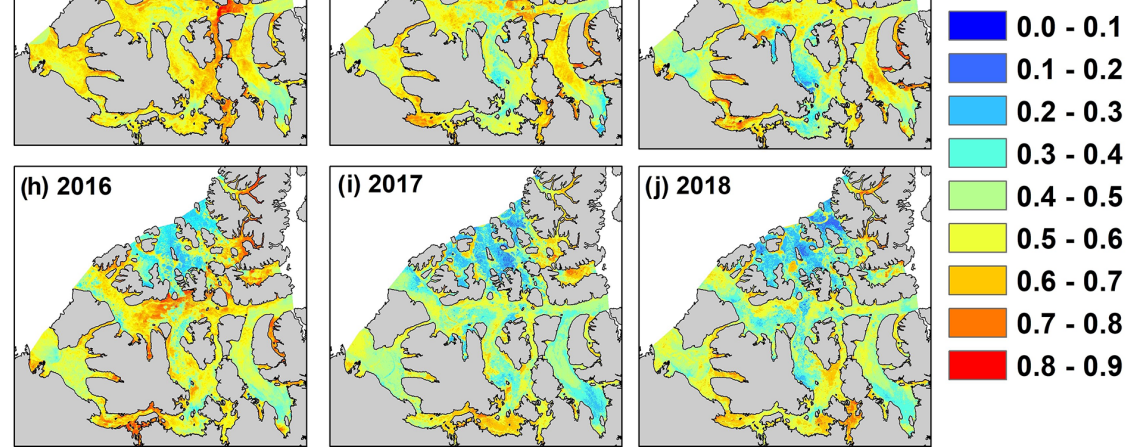

Figure 3. Spatial distribution of RADARSAT-2 peak melt pond fraction $\left(f_{\mathrm{pk}}\right)$ in the Canadian Arctic Archipelago from $2009-2018$ (a-j).

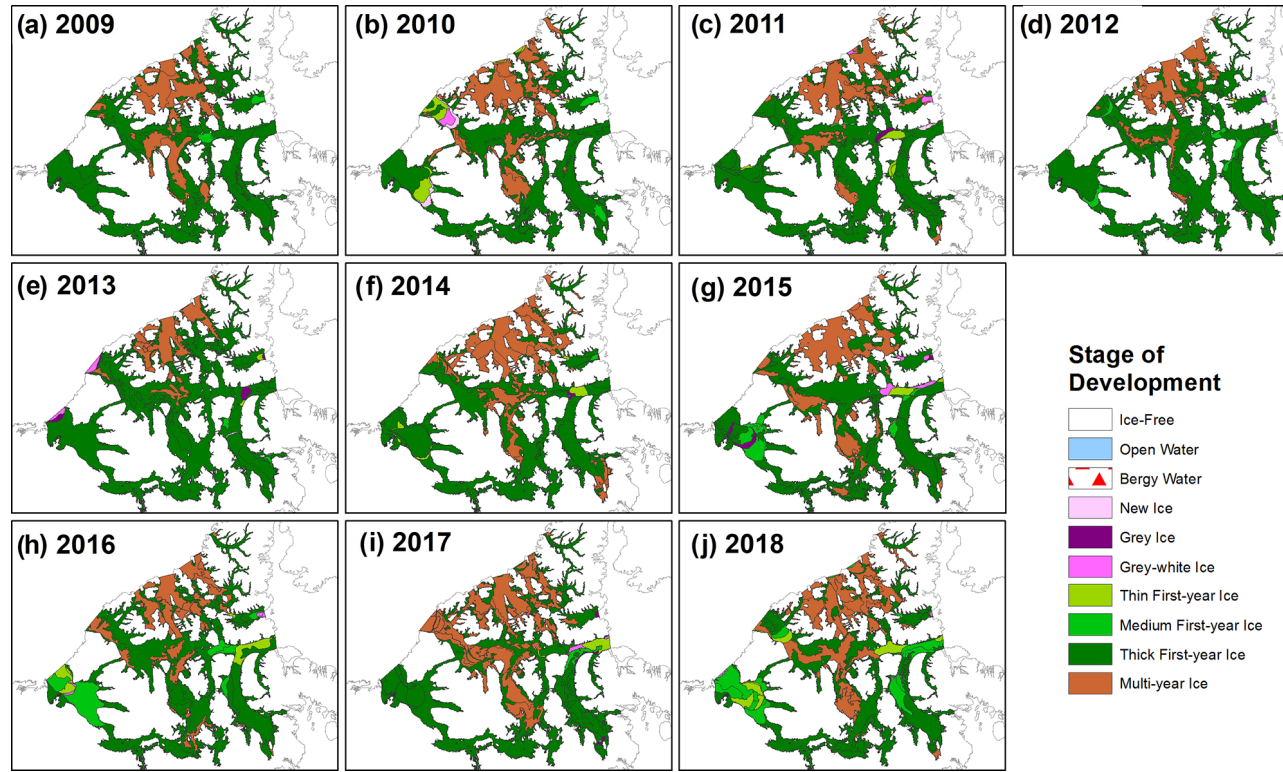

Figure 4. Spatial distribution of sea ice stage of development (type) in the first week of April in the Canadian Arctic Archipelago for 2009-2018 (a-j).

available April RADARSAT-2 imagery (Table 1) over all incidence angles in the CAA compared to only using images from Sentinel-1 within the CAA constrained to a certain incident angle range. As shown in Fig. 2, the uncertainty in RADARSAT- $2 f_{\mathrm{pk}}$ varies depending on the number of pixel overlaps (images). Overall, the $f_{\mathrm{pk}}$ distributions are in good agreement between both sensors.
The in situ evolution of $f_{\mathrm{p}}$ over FYI within the CAA acquired by Landy et al. (2014) allows us to place the RADARSAT- $2 f_{\mathrm{pk}}$ estimates within the melt pond stages of development classification system. Unfortunately, no MODIS $f_{\mathrm{p}}$ observations are located in close proximity to the in situ observations. The evolution of melt ponds on the surface of the sea ice has been classified into four distinct and 

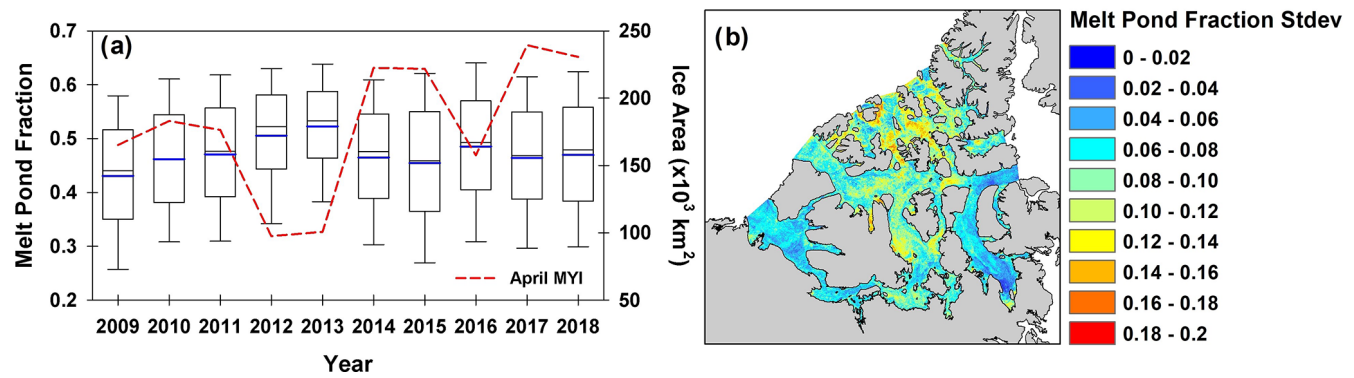

Figure 5. Boxplot time series of RADARSAT-2 peak melt pond fraction $\left(f_{\mathrm{pk}}\right)$ and mean April multi-year ice (MYI) area in the Canadian Arctic Archipelago for 2009-2018. The solid blue line represents the mean (a). Spatial distribution of the RADARSAT-2 $f_{\text {pk }}$ standard deviation from 2009-2018 (b).

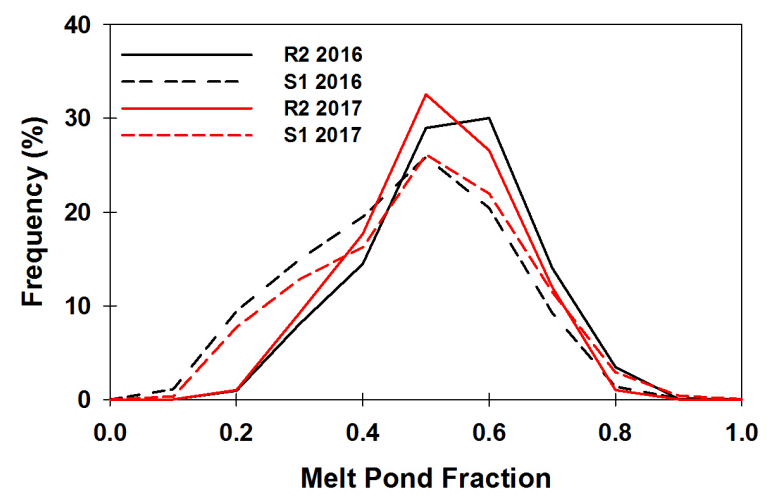

Figure 6. Frequency distribution (\%) of RADARSAT-2 peak melt pond fraction $\left(f_{\mathrm{pk}}\right)$ and Sentinel-1 $f_{\mathrm{pk}}$ from Scharien et al. (2017) in the Canadian Arctic Archipelago for 2016 and 2017.

consecutive stages. A brief description is provided here, and the reader is referred to Eicken et al. (2002) and Polashenski et al. (2012) for a more comprehensive description. In stage I, meltwater from snowmelt fills topographic depressions on the surface of the sea ice until the ponds reach their maximum areal extent. In stage II, melt pond coverage decreases due to horizontal water transport into macroscopic flaws and drainage through the ice. In stage III, the melt ponds typically drain through to the ocean and further changes in melt pond coverage depend on changes in surface topography and freeboard. Finally, in stage IV, melt ponds that survived the melt season refreeze and snow begins to accumulate on their surface.

Figure $7 \mathrm{a}$ compares the time series of the entire $100 \mathrm{~m} \mathrm{li}$ dar melt pond fraction coincident with the $f_{\mathrm{pk}}$ determined from RADARSAT-2 at the coinciding pixels. For 2011, RADARSAT- $2 f_{\mathrm{pk}}$ corresponds to the end of stage I and beginning of stage II, thus providing a very good representation of the seasonal peak of the $f_{\mathrm{p}}$, when the melt pond control on heat uptake and ice decay, through the ice-albedo feedback, is greatest. For 2012, RADARSAT- $2 f_{\mathrm{pk}}$ also corresponds to the end of stage I and beginning of stage II but is $\sim 0.2$ lower than in situ $f_{\mathrm{p}}$ values. This is likely due to the short duration
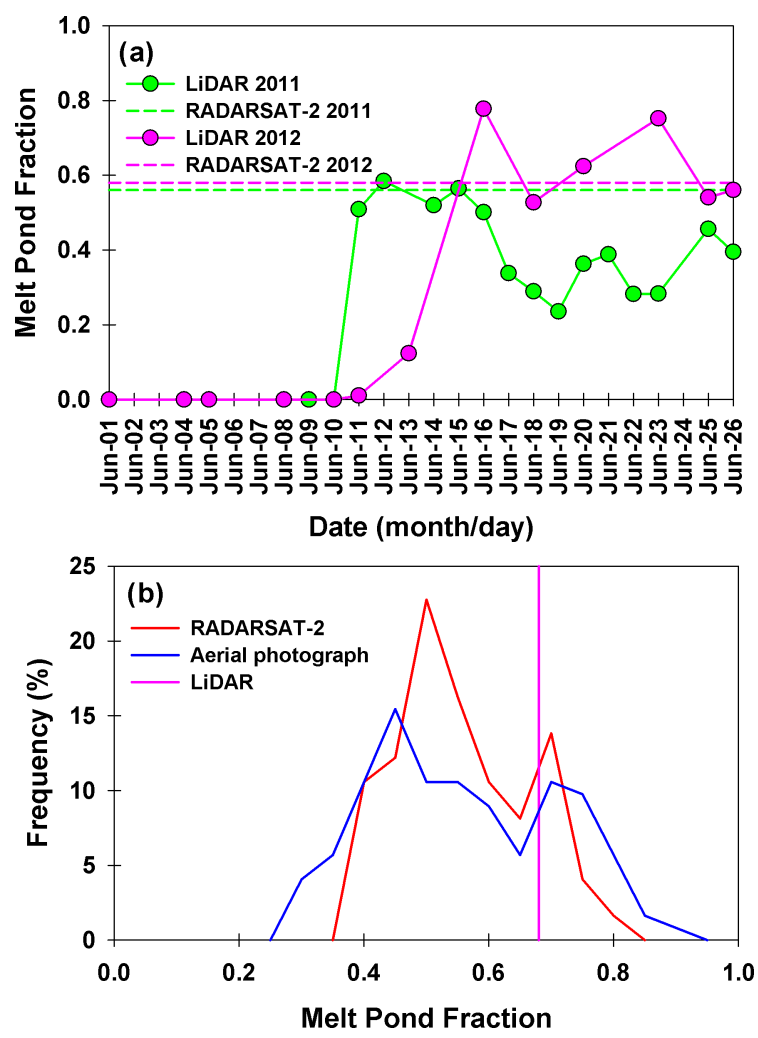

Figure 7. (a) Temporal evolution of observed melt pond fraction $\left(f_{\mathrm{p}}\right)$ and RADARSAT-2 peak melt pond fraction $\left(f_{\mathrm{pk}}\right)$ at in situ observation sites for $2011\left(74.7229^{\circ} \mathrm{N}, 95.1763^{\circ} \mathrm{W}\right)$ and $2012\left(74.7264^{\circ} \mathrm{N}, 95.5772^{\circ} \mathrm{W}\right)$. (b) Frequency distribution of RADARSAT- $2 f_{\mathrm{pk}}$ and aerial photograph $f_{\mathrm{p}}$ observations in Resolute Passage on 22 June 2012; the pink vertical link represents the mean lidar $f_{\mathrm{p}}$ on 22 June 2012.

but very high maximum $f_{\mathrm{p}}$ of 0.78 in 2012 as Scharien et al. (2017) found that Eq. (1) sometimes underestimates very high $f_{\mathrm{p}}$ due to the low $\gamma^{\circ}$ signal associated with very smooth FYI.

To give spatial context beyond the single-point comparison at the lidar site, Fig. $7 \mathrm{~b}$ shows the distribution of 
RADARSAT- $2 f_{\mathrm{pk}}$ and the $f_{\mathrm{p}}$ determined from aerial photo observations on 22 June 2012 near Resolute. The aerial photographs were acquired within 1 week of $f_{\mathrm{pk}}$ coverage being observed at the lidar site. The comparison was done by averaging all RADARSAT-2 pixels within each aerial photo (123 photos) which represents $\sim 861$ samples. The mean aerial photograph $f_{\mathrm{p}}$ was 0.54 and RADARSAT- $2 f_{\mathrm{pk}}$ was 0.53 with an the RMSE of 0.10 and bias of 0 . The distributions are in reasonably good agreement but RADARSAT- 2 values are slightly narrower than the distribution of $f_{\mathrm{p}}$ from the aerial photographs. It is likely the RADARSAT-2 distribution is narrow on the left tail because our method captures peak pond coverage, and some of the regions photographed were before or after their seasonal peak. We attribute the narrow right tail to the documented underestimation of Eq. (1) from Scharien et al. (2017). However, it is notable that both RADARSAT- 2 and the aerial photograph datasets capture the same bimodal $f_{\mathrm{p}}$ distribution, with the first mode around 0.4 0.5 characterizing rougher sea ice areas and the second mode around 0.7 capturing smooth flooded sea ice.

The seasonal time series of the $8 \mathrm{~d}$ composite MODIS $f_{\mathrm{p}}$, the maximum seasonal MODIS $f_{\mathrm{p}}$ and the predicted RADARSAT-2 $f_{\mathrm{pk}}$ for 2009-2011 is shown in Fig. 8 . MODIS $f_{\mathrm{p}}$ observations within the CAA indicate initial pond formation occurred in May for all years with $f_{\mathrm{pk}}$ reached in mid-July for 2009 and in early June for 2010 and 2011. Compared to the RADARSAT- $2 f_{\mathrm{pk}}$ values, the peak MODIS $f_{\mathrm{p}}$ is $\sim 0.20$ smaller. RADARSAT- $2 f_{\mathrm{pk}}$ is higher on average than MODIS because the MODIS $8 \mathrm{~d}$ product does not represent $f_{\mathrm{pk}}$. The MODIS $f_{\mathrm{p}}$ observations are determined weekly using $8 \mathrm{~d}$ composite image products that would include some melt pond formation and drainage processes prior to, and after, the seasonal peak. Moreover, MODIS $f_{\mathrm{p}}$ values are essentially aggregated from $500 \mathrm{~m}$ clear-sky pixels within a $12.5 \mathrm{~km} \times 12.5 \mathrm{~km}$ grid cell (Rösel et al., 2012) and the $500 \mathrm{~m}$ spatial resolution may limit detection of smaller pond fractions. Furthermore, not all of the $500 \mathrm{~m}$ pixels within the $12.5 \mathrm{~km} \times 12.5 \mathrm{~km}$ grid cell are likely to be at the same melt pond stage evolution. Finally, MODIS $f_{\mathrm{p}}$ observations give the time series of $f_{\mathrm{p}}$; therefore even the highest seasonal estimated MODIS $f_{\mathrm{p}}$ is reduced because while some regions of the CAA are at their seasonal peak others are behind or ahead. To that end, we also calculated the maximum $f_{\mathrm{p}}$ from MODIS regardless of timing during the melt season, for each pixel, also shown in Fig. 8. These values more closely compare with the RADARSAT- $2 f_{\mathrm{pk}}$ but are still $\sim 0.05$ smaller on average. Even the maximum $f_{\mathrm{p}}$ from MODIS is from an $8 \mathrm{~d}$ running mean of daily pond fraction estimates, so will underestimate the $f_{\mathrm{pk}}$ if the duration of peak ponding is $<8 \mathrm{~d}$. However, the top whisker of the box plot of the maximum $f_{\mathrm{p}}$ from MODIS indicates that MODIS does capture some regions at peak during the $8 \mathrm{~d}$ time series. Although we are using MODIS $f_{\mathrm{p}}$ product to compare against our RADARSAT$2 f_{\mathrm{pk}}$ estimates, Rösel et al. (2012) found that the MODIS $f_{\mathrm{p}}$ product also has errors up to $\sim 0.1$. Overall, MODIS $f_{\mathrm{p}}$ esti- mates are more representative of the seasonal mean $f_{\mathrm{p}}$ rather than $f_{\mathrm{pk}}$ within the CAA.

\subsection{Influence of RADARSAT-2 $f_{\mathrm{pk}}$ on summer sea ice area}

In order to investigate whether RADARSAT- $2 f_{\mathrm{pk}}$ values can be used to provide predictive information for summer sea ice area within the CAA, we separated the CAA into numerous predefined subregions and then determined the detrended correlations between RADARSAT- $2 f_{\mathrm{pk}}$ and weekly sea ice area from the CISDA regional ice charts in each region over the period of 2009-2018. We tested each week from the start of June to the end of September. The strongest correlation, together with the corresponding week of occurrence are shown in Fig. 9a and b, respectively. All the strongest correlations are negative, indicating - as expected - that years with higher predicted $f_{\mathrm{pk}}$ values are associated with lower sea ice area at a later point in the summer. The higher $f_{\mathrm{pk}}$ the lower the area-averaged albedo of the ice surface leading to accelerated melt and lower sea ice concentrations (e.g. Perovich and Polashenski, 2012). There is considerable spatial variability in the strongest correlation across the CAA with relatively low correlations in the majority of the northern CAA and very low correlations in the eastern regions of the CAA. The regions of Kellet-Crozier $(R=-0.92)$, Viscount Melville Sound $(R=-0.73)$, M'Clintock Channel $(R=-0.77)$, and Norwegian Bay $(R=-0.78)$ all exhibit statistically significant correlations above the $95 \%$ confidence level. In terms of timing for the statistically significant regions, RADARSAT-2 $f_{\mathrm{pk}}$ correlated the strongest to weekly sea ice area in August for all regions except Norwegian Bay (Fig. 9b). Compared to previous studies, the primary difference between using $f_{\mathrm{p}}$ values to predict summer sea ice conditions seems to be the timing of when the correlation is the strongest. Using simulated $f_{\mathrm{p}}$ values, Schröder et al. (2014) found the strongest correlation to September sea ice occurred for the May $f_{\mathrm{p}}$. Liu et al. (2015) used observed MODIS $f_{\mathrm{p}}$ values and reported the strongest correlation to September sea ice in late July. Our findings suggest that methods such as these may be able to predict August sea ice area from $f_{\mathrm{pk}}$ simulations or observations with higher confidence than September ice area, at least in the CAA.

Why is the relationship stronger in some regions of the CAA and weaker in others? RADARSAT- $2 f_{\mathrm{pk}}$ values are determined from imagery acquired in April when ice conditions in the CAA are landfast (immobile) and do not evolve in concert with sea ice dynamics operating within the CAA. As a result, RADARSAT- $2 f_{\text {pk }}$ values will not be spatially representative of the region's ice conditions when regionspecific dynamic breakup processes dominate over thermodynamics (i.e. in situ melt). In other words, the origin of the ice in these regions during the summer melt season will not always be the same as in April (i.e. pre-melt) when the initial RADARSAT- $2 f_{\mathrm{pk}}$ value was determined. The time 

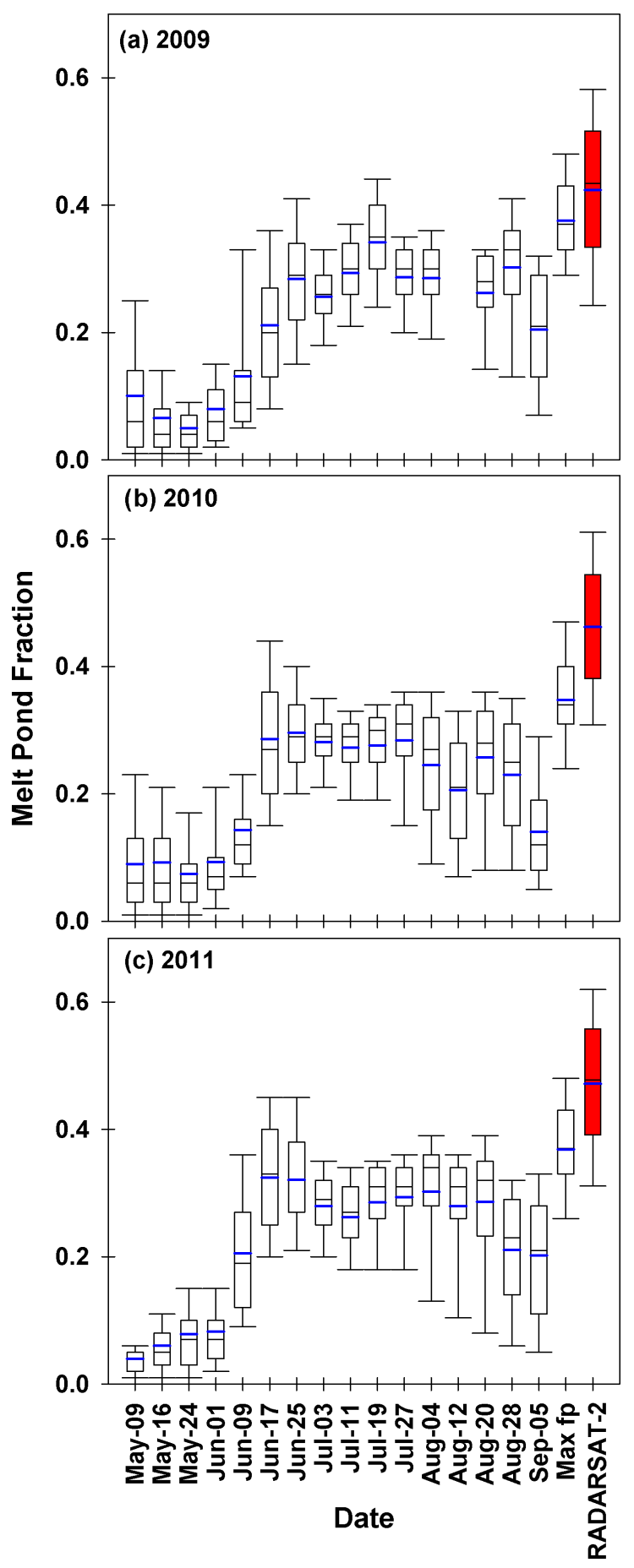

Figure 8. Boxplots of the seasonal time series of MODIS melt pond fraction $\left(f_{\mathrm{p}}\right)$, the maximum seasonal MODIS $f_{\mathrm{p}}$ and RADARSAT2 peak melt pond fraction $\left(f_{\mathrm{pk}}\right)$ for (a) 2009, (b) 2010 and (c) 2011. The solid blue line represents the mean. series of weekly detrended RADARSAT- $2 f_{\mathrm{pk}}$ and weekly sea ice area for selected regions within the CAA is shown in Fig. 10 and provides evidence for this regional dichotomy. In the Viscount Melville Sound and M'Clintock regions the correlations gradually get stronger, reaching a peak in August. These regions are known to be immobile and stagnant (e.g. Melling, 2002) with the majority of breakup taking place in September, which is when the relationship begins to degrade. The Kellet-Crozier is another stagnant region, which supports that in the absence of considerable ice dynamics the relationship between RADARSAT- $2 f_{\mathrm{pk}}$ and sea ice area is strong throughout the melt season. The time series in Penny Strait illustrates how the correlation gradually increases but when the region's dynamic breakup begins in July, ice is advected southward which degrades the correlation. This was also the case for many other regions in the northern CAA (not shown) as the flushing of sea ice southward from the northern CAA is a regular occurrence during the melt season (Melling, 2002; Howell et al., 2006). The low correlations in the southeastern regions of the CAA are also likely a function of ice dynamics as these regions of the CAA are known to be considerably influenced by currents and wind (Prinsenberg and Hamilton, 2005), and sea ice speed in Lancaster Sound and Barrow Strait can reach $10 \mathrm{~km} \mathrm{~d}^{-1}$ (Agnew et al., 2008).

The strong and statistically significant correlation in the Viscount Melville Sound region is encouraging as it is a key shipping region in the northern route of the Northwest Passage. To that end, we used linear regression to predict mean August sea ice area within Viscount Melville Sound with the detrended RADARSAT- $2 f_{\mathrm{pk}}$ values as a predictor. Figure 11 illustrates the results compared to observations (detrended) from the CISDA ice charts for 2009-2018. There is reasonable agreement between the predicted and observed sea ice area in the region with an RMSE of $18 \times 10^{3} \mathrm{~km}^{2}$ and an $R^{2}=0.44$. The largest discrepancies occurred for 2013 and 2014 with the RADARSAT- $2 f_{\mathrm{pk}}$ model prediction resulting in too little sea ice area. Overall, within the Viscount Melville Sound region of CAA there is a period for which a significant statistical relationship exists between RADARSAT- $2 f_{\mathrm{pk}}$ and the summer ice area before sea ice dynamics degrades the relationship.

\section{Conclusions}

In this study we predicted and analyzed spring $f_{\mathrm{pk}}$ using RADARSAT-2 within the CAA from 2009-2018. The spatial variability in RADARSAT- $2 f_{\text {pk }}$ was found to be excellent agreement with the spatial distribution of sea ice stage of development prior to the melt season as high (low) $f_{\mathrm{pk}}$ values were associated with FYI (MYI) types. The temporal variability of RADARSAT- $2 f_{\mathrm{pk}}$ over the 10 -year record was significantly correlated to April MYI area, highlighting the importance of MYI within the CAA. RADARSAT- $2 f_{\mathrm{pk}}$ was found to be in good agreement with the $f_{\mathrm{pk}}$ maximum 

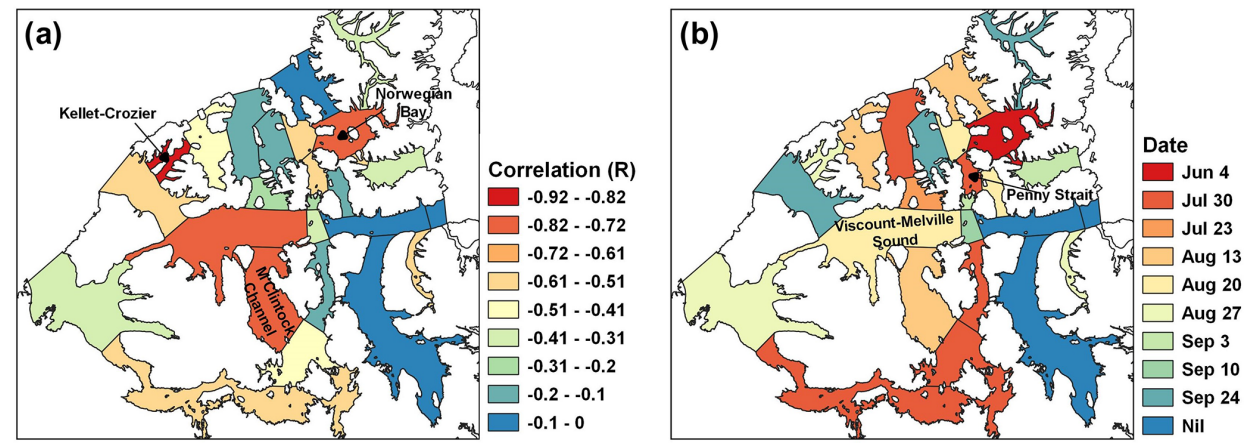

Figure 9. Spatial distribution of the (a) strongest detrended correlation $(R)$ between RADARSAT-2 peak melt pond fraction $\left(f_{\mathrm{pk}}\right)$ and weekly sea ice area and (b) week of occurrence.

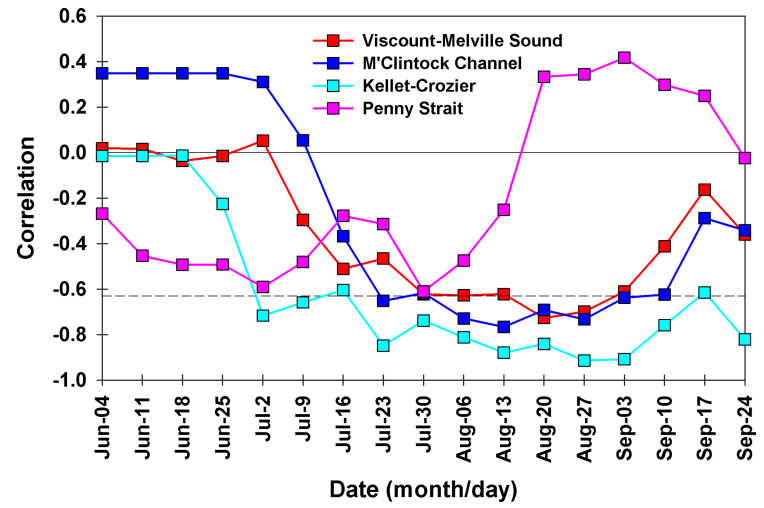

Figure 10. Time series of detrended correlations between RADARSAT-2 peak melt pond fraction $\left(f_{\mathrm{pk}}\right)$ and weekly sea ice area for selected regions in the Canadian Arctic Archipelago from June to September. The dashed black line is statistical significance at the $95 \%$ confidence level.

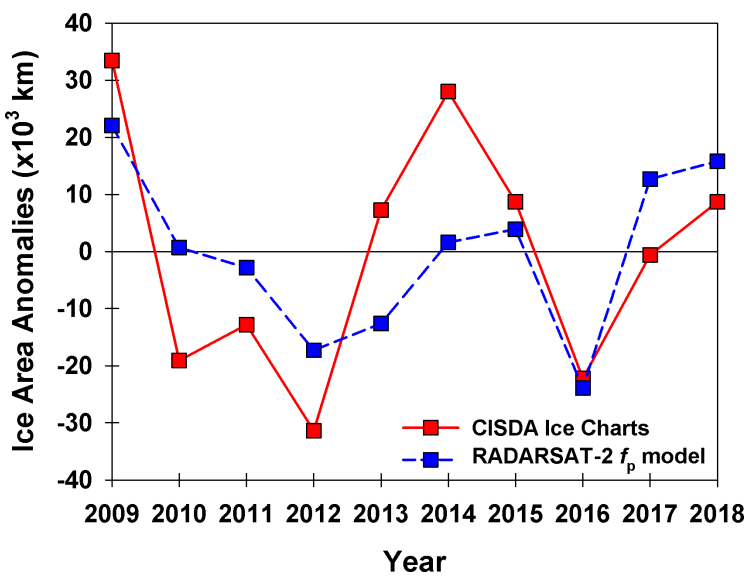

Figure 11. Predicated sea ice area anomalies (detrended) using RADARSAT-2 peak melt pond fraction $\left(f_{\mathrm{pk}}\right)$ and observed sea ice area anomalies (detrended) from the Canadian Ice Service Digital Archive (CISDA) ice charts in the Viscount Melville Sound region of the Canadian Arctic Archipelago, 2009-2018. extent observed in situ for 2011 but was slightly lower than 2012 when peak $f_{\mathrm{p}}$ was very large $(>0.7)$. Compared to peak MODIS $f_{\mathrm{p}}$ values, RADARSAT- $2 f_{\mathrm{pk}}$ values were larger by $\sim 0.05$. Based on our comparative analysis, RADARSAT$2 f_{\mathrm{pk}}$ is more representative of peak $f_{\mathrm{p}}$ within the CAA compared to the MODIS $8 \mathrm{~d}$ product, which on average was found to underestimate $f_{\mathrm{pk}}$ by $\sim 0.2$ and is more representative of the seasonal mean $f_{\mathrm{p}}$. We also found excellent agreement between RADARSAT- 2 and Sentinel-1, which suggests that combining both Sentinel-1 and the recently launched RADARSAT Constellation Mission (RCM) could facilitate pan-Arctic $f_{\mathrm{pk}}$ estimates. The RCM will also facilitate continued investigation of additional metrics that when combined with $\gamma^{\circ}$ could further improve predicted $f_{\mathrm{pk}}$.

The results presented in this study indicate that dynamically stable sea ice regions within the CAA exhibit a higher detrended correlation between RADARSAT- $2 f_{\mathrm{pk}}$ and summer sea ice area. Specifically, the strong and statistically significant de-trended correlation in the Viscount Melville Sound region demonstrates that RADARSAT- $2 f_{\mathrm{pk}}$ estimates are useful for providing predictive information about summer sea ice area in the northern route of the Northwest Passage. This information could find utility in constraining regional model simulations (e.g. Lemieux et al., 2016). Alternatively, it could be advantageous to exploit the high spatial resolution of SAR and investigate whether local-scale $f_{\mathrm{pk}}$ estimates could enhanced knowledge of summer ice conditions in northern communities (e.g. Cooley et al., 2020). Ultimately, imagery from RCM will ensure our time series of RADARSAT- $2 f_{\text {pk }}$ estimates in the CAA will continue, gradually building statistics and facilitating the development of more robust statistical relationships in upcoming years.

Data availability. RADARSAT-2 imagery is available online for a fee from the Earth Observation Data Management System (https://www.eodms-sgdot.nrcan-rncan.gc.ca, last access: 16 December 2020; Government of Canada, 2020a). RADARSAT2-derived melt pond fraction is available through the lead author Stephen E. L. Howell (stephen.howell@canada.ca). 
The MODIS Arctic melt pond cover fraction dataset is available from the Integrated Climate Data Center (ICDC, https://icdc.cen.uni-hamburg.de/, last access: 16 December 2020; Universität Hamburg, 2020). The CISDA is available online from the Canadian Ice Service (CIS; https://www.canada.ca/en/ environment-climate-change/services/ice-forecasts-observations/ latest-conditions/archive-overview.html, last access: 16 December 2020; Government of Canada, 2020b). In situ melt pond data are available through contributing author Jack Landy (jack.landy@bristol.ac.uk), and the melt pond aerial photograph data are available through contributing author Randall K. Scharien (randy@uvic.ca).

Author contributions. SELH wrote the manuscript with input from all authors. SELH, RKS, and MB preformed the analysis.

Competing interests. The authors declare that they have no conflict of interest.

Financial support. Funding for RKS provided by Polar Knowledge Canada Science and Technology program (grant no. NST-1718-0024) and Marine Environmental Observation Prediction and Response Network (MEOPAR) (project no. 1-0202-012.5). Jack Landy is supported by the European Space Agency Living Planet Fellowship "Arctic-SummIT" (grant no. ESA/4000125582/18/I-NS) and the Natural Environment Research Council (grant nos. "PRE-MELT" NE/T000546/1 and "DiatomARCTIC” NE/R012849/1).

Review statement. This paper was edited by Ludovic Brucker and reviewed by three anonymous referees.

\section{References}

Agnew, T., Lambe, A., and Long, D.: Estimating sea ice area flux across the Canadian Arctic Archipelago using enhanced AMSR-E, J. Geophys. Res., 113, C10011, https://doi.org/10.1029/2007JC004582, 2008.

Chevallier, M., Salas, D., Mélia, Y., Voldoire, A., Déqué, M., and Garric, G.: Seasonal forecasts of the pan-Arctic sea ice extent using a GCM-based seasonal prediction system, J. Climate, 26, 6092-6104, https://doi.org/10.1175/JCLI-D-12-00612.1, 2013

Cooley, S. W., Ryan, J. C., Smith, L. C., Horvat, C., Pearson, B., Dale, B., and Lynch, A. H.: Coldest Canadian Arctic communities face greatest reductions in shorefast sea ice, Nat. Clim. Change, 10, 533-538, https://doi.org/10.1038/s41558-020-07575, 2020.

Dumas, J. A., Flato, G. M., and Brown, R. D.: Future projections of landfast ice thickness and duration in the Canadian Arctic, J. Climate, 19, 5175-5189, 2006.

Eicken, H.: Ocean science: Arctic sea ice needs better forecasts, Nature, 497, 431-433, https://doi.org/10.1038/497431a, 2013.
Eicken, H., Krouse, H. R., Kadko, D., and Perovich, D. K.: Tracer studies of pathways and rates of meltwater transport through Arctic summer sea ice, J. Geophys. Res., 107, 8046, https://doi.org/10.1029/2000JC000583, 2002.

Eicken, H., Grenfell, T. C., Perovich, D. K., Richter-Menge, J. A., and Frey, K.: Hydraulic controls of summer Arctic pack ice albedo, J. Geophys. Res., 109, C08007, https://doi.org/10.1029/2003JC001989, 2004.

Flocco, D., Feltham, D. L., and Turner, A. K.: Incorporation of a physically based melt pond scheme into the sea ice component of a climate model, J. Geophys. Res., 115, C08012, https://doi.org/10.1029/2009JC005568, 2010.

Flocco, D., Schröder, D., Feltham, D. L., and Hunke, E. C.: Impact of melt ponds on Arctic sea ice simulations from 1990 to 2007, J. Geophys. Res., 117, C09032, https://doi.org/10.1029/2012JC008195, 2012.

Fors, A. S., Divine, D. V., Doulgeris, A. P., Renner, A. H. H., and Gerland, S.: Signature of Arctic first-year ice melt pond fraction in X-band SAR imagery, The Cryosphere, 11, 755-771, https://doi.org/10.5194/tc-11-755-2017, 2017.

Grenfell, T. C. and Perovich, D. K.: Seasonal and spatial evolution of albedo in a snow-ice-land-ocean environment, J. Geophys. Res., 109, C01001, https://doi.org/10.1029/2003JC001866, 2004.

Government of Canada: Canadian Ice Service archive: overview, available at: https://www.eodms-sgdot.nrcan-rncan.gc.ca, last access: 16 December 2020a.

Government of Canada: Earth Observation Data Management System, available at: https://www. canada.ca/en/environment-climate-change/services/ ice-forecasts-observations/latest-conditions/archive-overview. html, last access: 16 December 2020b.

Guemas, V., Chevallier, M., Déqué, M., Bellprat, O., and DoblasReyes, F.: Impact of sea ice initialization on sea ice and atmosphere prediction skill on seasonal timescales, Geophys. Res. Lett., 43, 3889-3896, https://doi.org/10.1002/2015GL066626, 2016.

Howell, S. E. L. and Brady, M.: The dynamic response of sea ice to warming in the Canadian Arctic Archipelago, Geophys. Res. Lett., 46, 13119-13125, https://doi.org/10.1029/2019GL085116, 2019.

Howell, S. E. L., Tivy, A., Yackel, J. J., and Scharien, R. K.: Application of a SeaWinds/QuikSCAT sea ice melt algorithm for assessing melt dynamics in the Canadian Arctic Archipelago, J. Geophys. Res.-Oceans, 111, C07025, https://doi.org/10.1029/2005JC003193, 2006.

Howell, S. E. L., Wohlleben, T., Komarov, A., Pizzolato, L., and Derksen, C.: Recent extreme light sea ice years in the Canadian Arctic Archipelago: 2011 and 2012 eclipse 1998 and 2007, The Cryosphere, 7, 1753-1768, https://doi.org/10.5194/tc7-1753-2013, 2013.

Howell, S. E. L., Laliberté, F., Kwok, R., Derksen, C., and King, J.: Landfast ice thickness in the Canadian Arctic Archipelago from observations and models, The Cryosphere, 10, 1463-1475, https://doi.org/10.5194/tc-10-1463-2016, 2016.

Hu, X., Sun, J., Chan, T. O., and Myers, P. G.: Thermodynamic and dynamic ice thickness contributions in the Canadian Arctic Archipelago in NEMO-LIM2 numerical simulations, The 
Cryosphere, 12, 1233-1247, https://doi.org/10.5194/tc-12-12332018, 2018.

Istomina, L., Heygster, G., Huntemann, M., Schwarz, P., Birnbaum, G., Scharien, R., Polashenski, C., Perovich, D., Zege, E., Malinka, A., Prikhach, A., and Katsev, I.: Melt pond fraction and spectral sea ice albedo retrieval from MERIS data - Part 1: Validation against in situ, aerial, and ship cruise data, The Cryosphere, 9, 1551-1566, https://doi.org/10.5194/tc9-1551-2015, 2015.

Kwok, R.: Arctic sea ice thickness, volume, and multiyear ice coverage: losses and coupled variability (1958-2018), Environ. Res. Lett., 13, 105005, https://doi.org/10.1088/17489326/aae3ec, 2018.

Laliberté, F., Howell, S. E. L., and Kushner, P. J.: Regional variability of a projected sea ice-free Arctic during the summer months, Geophys. Res. Lett., 43, 256-263, https://doi.org/10.1002/2015GL066855, 2016.

Laliberté, F., Howell, S. E. L., Lemieux, J.-F., Dupont, F., and Lei, J.: What historical landfast ice observations tell us about projected ice conditions in Arctic archipelagoes and marginal seas under anthropogenic forcing, The Cryosphere, 12, 3577-3588, https://doi.org/10.5194/tc-12-3577-2018, 2018.

Landy, J. C., Ehn, J. K., Shields, M., and Barber, D. G.: Surface and melt pond evolution on landfast first-year sea ice in the Canadian Arctic Archipelago, J. Geophys. Res., 119, 3054-3075, 2014.

Landy, J. C., Ehn, J. K., and Barber, D. G.: Albedo feedback enhanced by smoother Arctic sea ice, Geophys. Res. Lett., 42, 710 714, https://doi.org/10.1002/2015GL066712, 2015.

Lee, S., Stroeve, J. C., Tsamados, M., and Khand, A.L.: Machine learning approaches to retrieve pan-Arctic melt ponds from visible satellite imagery, Remote Sens. Environ., 247, 111919, https://doi.org/10.1016/j.rse.2020.111919, 2020.

Lemieux, J.-F., Beaudoin, C., Dupont, F., Roy, F., Smith, G.C., Shlyaeva, A., Buehner, M., Caya, A., Chen, J., Carrieres, T., Pogson, L., DeRepentigny, P., Plante, A., Pestieau, P., Pellerin, P., Ritchie, H., Garric, G., and Ferry, N.: The Regional Ice Prediction System (RIPS): verification of forecast sea ice concentration, Q. J. Roy. Meteor. Soc, 142, 632-643, https://doi.org/10.1002/qj.2526, 2016.

Li, H., Perrie, W., Li, Q., and Hou, Y.: Estimation of melt pond fractions on first year sea ice using compact polarization SAR, J. Geophys. Res., 122, 8145-8166, https://doi.org/10.1002/2017JC013248, 2017.

Liu, J., Song, M. H., Horton R. M., and Hu, Y.: Revisiting the potential of melt pond fraction as a predictor for the seasonal Arctic sea ice extent minimum, Environ. Res. Lett., 10, 5, https://doi.org/10.1088/1748-9326/10/5/054017, 2015.

Markus, T., Cavalieri, D. J., Tschudi, M. A., and Ivanoff, A.: Comparison of aerial video and Landsat 7 data over ponded sea ice, Remote Sens. Environ., 86, 458-469, 2003.

Maslanik, J., Stroeve, J., Fowler, C., and Emery, W.: Distribution and trends in Arctic sea ice age through spring 2011, Geophys. Res. Lett., 38, L13502, https://doi.org/10.1029/2011GL047735, 2011.

Melling, H.: Sea ice of the northern Canadian Arctic Archipelago, J. Geophys. Res., 107, 3181, https://doi.org/10.1029/2001JC001102, 2002.
Peng, G. and Meier, W. M.: Temporal and regional variability of Arctic sea-ice coverage from satellite data, Ann. Glaciol., 59, 191-200, https://doi.org/10.1017/aog.2017.32, 2017.

Perovich, D. K. and Polashenski., C.: Albedo evolution of seasonal Arctic sea ice, Geophys. Res. Lett., 39, L08501, https://doi.org/10.1029/2012GL051432, 2012.

Perovich, D. K., Grenfell, T. C., Light, B., and Hobbs, P. V.: Seasonal evolution of the albedo of multiyear Arctic sea ice, J. Geophys. Res., 107, 8044, https://doi.org/10.1029/2000JC000438, 2002.

Petty, A. A., Kurtz, N. T., Kwok, R., Markus, T., and Neumann, T. A.: Winter Arctic sea ice thickness from ICESat2 freeboards, J. Geophys. Res.-Oceans, 125, e2019JC015764, https://doi.org/10.1029/2019JC015764, 2020.

Pizzolato, L., Howell, S. E. L., Derksen, C., Dawson, J., and Copland, L.: Changing sea ice conditions and marine transportation activity in Canadian Arctic waters between 1990 and 2012, Climatic Change, 123, 161-173, https://doi.org/10.1007/s10584013-1038-3, 2014.

Polashenski, C., Perovich, D. K., and Courville, Z.: The mechanisms of sea ice melt pond formation and evolution, J. Geophys. Res., 117, C01001, https://doi.org/10.1029/2011JC007231, 2012.

Prinsenberg, S. J. and Hamilton, J.: Monitoring the volume, freshwater and heat fluxes passing through Lancaster sound in the Canadian Arctic Archipelago, Atmos.-Ocean, 43, 1-22, https://doi.org/10.3137/ao.430101, 2005.

Rösel, A., Kaleschke, L., and Birnbaum, G.: Melt ponds on Arctic sea ice determined from MODIS satellite data using an artificial neural network, The Cryosphere, 6, 431-446, https://doi.org/10.5194/tc-6-431-2012, 2012.

Scharien, R. K., Hochheim, K., Landy, J., and Barber, D. G.: First-year sea ice melt pond fraction estimation from dualpolarisation C-band SAR - Part 2: Scaling in situ to Radarsat2, The Cryosphere, 8, 2163-2176, https://doi.org/10.5194/tc-82163-2014, 2014.

Scharien, R. K., Segal, R., Nasonova, S., Nandan, V., Howell, S. E. L., and Haas, C.: Winter Sentinel-1 backscatter as a predictor of spring Arctic sea ice melt pond fraction, Geophys. Res. Lett., 44, 12262-12270, https://doi.org/10.1002/2017GL075547, 2017.

Serreze, M. C., Holland, M. M., and Stroeve, J.: Perspectives on the Arctic's shrinking sea-ice cover, Science, 315, 1533-1536, 2007.

Schröder, D., Feltham, D. L., Flocco, D., and Tsamados, M.: September Arctic sea-ice minimum predicted by spring melt-pond fraction, Nat. Clim. Change, 4, 353-357, https://doi.org/10.1038/nclimate2203, 2014.

Sigmond, M., Fyfe, J. C., Flato, G. M., Kharin, V. V., and Merryfield, W. J.: Seasonal forecast skill of Arctic sea ice area in a dynamical forecast system, Geophys. Res. Lett., 40, 529-534, https://doi.org/10.1002/grl.50129, 2013.

Skyllingstad, E. D. and Polashenski, C.: Estimated heat budget during summer melt of Arctic first-year sea ice Geophys. Res. Lett., 45, 11789-11797, https://doi.org/10.1029/2018GL080349, 2018.

Small, D.: Flattening gamma: Radiometric terrain correction for SAR imagery, IEEE T. Geosci. Remote S., 49, 3081-3093, https://doi.org/10.1109/TGRS.2011.2120616, 2011. 
Sou, T. and Flato, G.: Sea ice in the Canadian Arctic Archipelago: Modeling the past (1950-2004) and the future (2041-60), J. Climate, 22, 2181-2198, 2009.

Stroeve, J. C., Serreze, M. C., Holland, M. M., Kay, J. E., Maslanik, J., and Barrett, A. P.: The Arctic's rapidly shrinking sea ice cover: A research synthesis, Climatic Change, 110, 1005-1027, https://doi.org/10.1007/s10584-011-0101-1, 2012.

Tivy, A., Howell, S. E. L., Alt, B., McCourt, S., Chagnon, R., Crocker, G., Carrieres, T., and Yackel, J. J.: Trends and variability in summer sea ice cover in the Canadian Arctic based on the Canadian Ice Service Digital Archive, 1960-2008 and 1968-2008, J. Geophys. Res., 116, C03007, https://doi.org/10.1029/2009JC005855, 2011.

Tschudi, M. A., Maslanik, J. A., and Perovich, D. K.: Derivation of melt pond coverage on arctic sea ice using MODIS observation, Remote Sens. Environ., 112, 2605-2614, 2008.
Tschudi, M. A., Meier, W. N., and Stewart, J. S.: An enhancement to sea ice motion and age products at the National Snow and Ice Data Center (NSIDC), The Cryosphere, 14, 1519-1536, https://doi.org/10.5194/tc-14-1519-2020, 2020.

Universität Hamburg: Integrated Climate Data Center - ICDC, available at: https://icdc.cen.uni-hamburg.de/, last access: 16 December 2020.

Webster, M. A., Rigor, I. G., Perovich, D. K., Richter-Menge, J. A., Polashenski, C. M., and Light, B.: Seasonal evolution of melt ponds on Arctic sea ice, J. Geophys. Res., 120, 5968-5982, https://doi.org/10.1002/2015JC011030, 2015. 